\title{
Activation of the Trace Amine-Associated Receptor I Prevents Relapse to Cocaine Seeking
}

\author{
Yui Pei ${ }^{1,6}$, Jungah Lee ${ }^{1,6}$, Damiana Leo ${ }^{2}$, Raul R Gainetdinov ${ }^{2,3,4}$, Marius C Hoener ${ }^{5}$ and Juan J Canales*, \\ 'Behavioural Neuroscience, Department of Psychology, University of Canterbury, Christchurch, New Zealand; '2Department of Neuroscience and \\ Brain Technologies, Italian Institute of Technology, Genoa, Italy; ${ }^{3}$ Skolkovo Institute of Science and Technology, Skolkovo, Russia; ${ }^{4}$ Faculty of Biology \\ and Soil Science, St Petersburg State University, St Petersburg, Russia; ${ }^{5}$ Neuroscience Research, Pharmaceuticals Division, F Hoffmann-La Roche, \\ Basel, Switzerland
}

\begin{abstract}
The trace amine-associated receptor I (TAARI) has emerged as a promising target for medication development in addiction because of its ability to regulate dopamine (DA) transmission. We tested in rats the efficacy of RO5203648 and RO5256390, partial and full TAAR I agonists, respectively, in models of cocaine relapse. Using a model of context-induced relapse, both RO5203648 and RO5256390 dosedependently suppressed cocaine seeking after a 2-week period of withdrawal from chronic cocaine self-administration. In a model of extinction-reinstatement, RO5203648 completely inhibited cocaine-primed reinstatement of cocaine seeking. At doses that effectively suppressed cocaine seeking neither RO5203648 nor RO5256390 altered responding maintained by a natural reward. Moreover, fast scan cyclic voltammetry data showed that RO5203648 prevented cocaine-induced DA overflow in the nucleus accumbens without altering DA half-life, suggesting that the partial TAARI agonist attenuated cocaine-stimulated DA overflow by mechanisms other than direct interference with DA uptake. Collectively, these data provide strong evidence in support of TAARI as a neuropharmacological target for the treatment of cocaine addiction.

Neuropsychopharmacology (20I4) 39, 2299-2308; doi: I 0.I038/npp.20 I4.88; published online I4 May 20 I4
\end{abstract}

\section{INTRODUCTION}

Trace amines (TAs), such as p-tyramine, $\beta$-phenylethylamine, tryptamine, and octopamine, are a family of endogenous molecules with strong similarities to classical monoamines (Berry, 2007; Grandy, 2007). Known for decades, TAs were at first believed to act through the defined effector systems associated with classical biogenic amines. However, the cloning of mammalian G proteincoupled receptors that stimulate the production of cAMP when exposed to TAs (Bunzow et al, 2001; Borowsky et al, 2001), and the identification of such receptors in the brain (Miller et al, 2005; Xie et al, 2007), supports the role of TAs as neurotransmitters in their own right. Two receptors, referred to as the TA-associated receptor (TAAR) 1 and 4 subtypes, have been found to be sensitive to TAs at physiological concentrations, but only TAAR1 has been identified and cloned in human, monkey, rat, and mouse genomes (Lindemann et al, 2005), with TAAR4 being a pseudogene in human. Recent evidence supports a role for TAAR1 in the regulation of dopamine (DA) transmission

*Correspondence: Dr JJ Canales, Behavioural Neuroscience, Department of Psychology, University of Canterbury, Private Bag 4800, Christchurch 8|40, New Zealand, Tel: +64 33642987 Ext. 7005 (office) 7303 (lab), Fax: + 643364 2181, E-mail: juan.canales@canterbury.ac.nz

${ }^{6}$ These authors contributed equally to this work.

Received 3I December 20 13; revised 22 March 20 I4; accepted 4 April 2014; accepted article preview online II April 2014 and psychostimulant action. First, psychostimulant and hallucinogenic compounds, such as amphetamine, methamphetamine, 3,4-methylenedioxymethamphetamine, and lysergic acid diethylamide, are all agonists at TAAR1 (Bunzow et al, 2001; Reese et al, 2014) and the rank order of potency of several enantiomeric amphetamines to activate TAAR1 is correlated with stimulant effects reported in humans (Lewin et al, 2011). Second, TAs evoke 'amphetamine-like', sympathomimetic effects at high nanomolar to low micromolar concentrations, which has been linked to increased monoamine release and inhibition of monoamine uptake (Berry, 2004; Lindemann and Hoener, 2005). By contrast, TAs may in the low nanomolar range contribute to monoamines' homeostasis as revealed by genetic and pharmacological studies. Taarl knockout mice showed elevated spontaneous discharge of DA neurons in the ventral tegmental area (VTA) and enhanced sensitivity to the locomotor and DA-enhancing effects of amphetamine (Lindemann et al, 2008), whereas brain-specific overexpression of TAAR1 rendered mice hyposensitive to the neurochemical and locomotor-stimulating effects of amphetamine (Revel et al, 2012a). Furthermore, the TAAR1 partial agonist, RO5203648, reduced cocaine-stimulated locomotor activity and cocaine intake in a self-administration (S-A) paradigm (Revel et al, 2012b). These findings support a role for TAAR1 in the regulation of dopaminergic transmission and psychomotor stimulant action. However, despite their promising profile, the potential of TAAR1 
selective compounds to reduce relapse after chronic stimulant S-A, a highly desirable feature for an efficacious anti-addiction medication to have, has not been previously investigated.

Here, to address this important question, we used RO5203648 and RO5256390, partial and full TAAR1 agonists, respectively (Revel et al, 2012b, 2013), and wellestablished models of cocaine S-A, including contextinduced relapse and extinction-reinstatement, coupled with neurochemical assays. We show that both RO5203648 and RO5256390 prevented relapse to cocaine seeking after withdrawal from cocaine S-A. Moreover, RO5203648 reduced cocaine's reinforcing efficacy, blocked cocaine-primed reinstatement of cocaine seeking and attenuated cocainestimulated increases in DA overflow in the nucleus accumbens, strongly supporting the development of TAAR1 agonists as candidate medications for cocaine addiction.

\section{MATERIALS AND METHODS}

\section{Subjects}

Long Evans male rats (8- to 10-week old at the start of the experiments) served as subjects. Rats were obtained from the Department of Psychology (University of Canterbury, Christchurch, New Zealand) or Charles River (Milan, Italy) and maintained on a reversed 12-h light-dark cycle (light on at 2000 hours) and standard conditions of temperature $\left(21 \pm 2{ }^{\circ} \mathrm{C}\right)$ and humidity (45-55\%). Rats used in the S-A studies were given a $20 \mathrm{~g} /$ day ration of rat chow and free access to water (Velazquez-Sanchez et al, 2013). All procedures were carried out in accordance with the NIH Guide for the Care and Use of Laboratory animals, and were approved by the animal ethics committees of the University of Canterbury and of the Italian Institute of Technology.

\section{Pharmacological Agents}

Cocaine hydrochloride was obtained from the National Institute on Drug Abuse (USA). It was dissolved in $0.9 \%$ $\mathrm{NaCl}$ for intraperitoneal injections and intravenous S-A. RO5203648 and RO5256390 were synthesized at F HoffmanLa Roche. Both compounds were dissolved in $10 \%$ dimethylsulfoxide and $0.9 \%$ saline.

\section{Catheter Implantation Surgery}

Rats assigned to the cocaine S-A experiments were operated on to implant intravenous catheters. Animals were anesthetized with 2,2,2-tribromoethanol solution $(12.5 \mathrm{mg} / \mathrm{ml} \mathrm{solu-}$ tion in $2.5 \%$ tertiary amyl alcohol, $2 \mathrm{ml} / 100 \mathrm{~g}$ of body weight). Catheters (o.d. $0.63 \mathrm{~mm}$, i.d. $0.30 \mathrm{~mm}$, Camcaths, UK) were subcutaneously placed on the back of the animal between the scapulae and the tip of the silicon tube was inserted and fixed to the right jugular vein. Immediately after surgery, rats were treated with the analgesic, carprofen $(5 \mathrm{mg} / \mathrm{kg})$. To prevent infections, rats were treated pre and post-surgically with daily injections of antibiotic (cephalexin, $25 \mathrm{mg} / \mathrm{kg}$ s.c., Norbrook, New Zealand). To prolong their patency, catheters were flushed with heparinized saline $(0.1 \mathrm{ml}, 70 \mathrm{IU} / \mathrm{ml})$ before and after each S-A session.

\section{Apparatus}

Twelve S-A chambers (Med Associates, VT) controlled by software (Med-PC IV) were used in the S-A studies. Chambers had two response levers designated as active and inactive. Active lever presses resulted in activation of the infusion pump and a light stimulus for $5 \mathrm{~s}$. Presses on the inactive lever were recorded but had no programmed consequences. Each experimental chamber was enclosed in a sound-attenuating box. The house light was on during S-A and relapse sessions. Rats were connected to a liquid swivel with polyethylene-50 tubing protected by a metal spring. In the food S-A experiments, each lever press resulted in delivery of a chocolate-flavored pellet ( $45 \mathrm{mg}$, Bio-Serve, NJ) into a food magazine situated between the two levers.

\section{S-A Training and Relapse Procedures}

Rats were trained to lever press for cocaine $(0.5 \mathrm{mg} / \mathrm{kg} /$ infusion) or saline. Injections were administered as $0.1 \mathrm{ml}$ boluses. Rats were progressively trained under a fixed-ratio (FR) 1, FR2 and finally FR3 schedules during long-access sessions. Schedule progression was dependent on meeting a criterion (number of infusions per session $\geqslant 30$ ). Rats were then transferred to daily 90 -min sessions. Cocaine infusions were limited to a maximum of 40 to prevent overdosing. Rats were trained until a criterion of consistency and stability was met during the daily 90 -min sessions (number of infusions per session $\geqslant 15$ for 5 consecutive days with $<20 \%$ variability).

In the experiments involving relapse in the presence of contextual cues, withdrawal from cocaine S-A was introduced after completion of the training phase. Rats were not given access to the S-A chambers for 14 days. After abstinence, rats underwent relapse to drug seeking by placing them in the S-A context (ie, S-A chamber with the two levers exposed) for $45 \mathrm{~min}$. Each rat completed three drug-seeking tests on alternate days. Rats received treatment with RO5203648 (0, 3, $10 \mathrm{mg} / \mathrm{kg}$ i.p.) or RO5256390 (0, $3,10 \mathrm{mg} / \mathrm{kg}$ i.p.) $15 \mathrm{~min}$ before the relapse test.

In the experiments involving reinstatement of drug seeking by cocaine priming, after S-A training four separate groups of rats underwent extinction session during which lever press was not reinforced (neither by infusions nor the stimulus light). Daily 90-min extinction sessions were conducted until a criterion was met during 3 consecutive days (ie, active lever presses $\leqslant 10 \%$ of the average number of active lever presses maintained during the last five sessions of cocaine S-A). Rats that did not meet this criterion after 21 extinction sessions were excluded from this study. After the extinction phase, rats underwent reinstatement tests in which reinstatement of drug-seeking behavior was assessed by giving cocaine $(10 \mathrm{mg} / \mathrm{kg}$, i.p.) or saline before the start of the sessions. To minimize carry over effects, each rat was tested only twice for reinstatement. Treatments were assigned randomly. To assess the effects of RO5203648 on drug-induced reinstatement, rats were divided into three experimental groups receiving a pretreatment of RO5203648 (0, 3, or $10 \mathrm{mg} / \mathrm{kg}$, i.p.) $15 \mathrm{~min}$ before cocaine or saline injection. In between the two reinstatement tests, rats underwent daily 90 -min extinction sessions to ensure that active lever presses returned to 
pre-reinstatement levels for 2 consecutive days. The reinstatement sessions were identical to extinction session except that they lasted for $3 \mathrm{~h}$. A separate group of rats responding for saline during the S-A phase $(n=5)$ controlled for potential nonspecific effects of cocaine on the reinstatement test, and also received the RO5203648 pretreatments.

\section{Progressive-Ratio (PR) Tests}

A group of rats $(n=9)$ was trained on cocaine S-A under FR3 schedule in 90-min daily sessions until they achieved a stability criterion (number of infusions per session $\geqslant 15$ for 3 consecutive days with $<20 \%$ variability). Each rat was subjected to three PR tests in which RO5203648 $(0,3$, or $10 \mathrm{mg} / \mathrm{kg}$ ) was administered in counterbalanced manner $15 \mathrm{~min}$ before the start of the session. The PR tests were conducted on 3 different days separated by at least one standard cocaine S-A session (ie, 90-min FR3 cocaine S-A session with number of infusions $\geqslant 15$ ). All the rats (except one) required only one FR3 90-min session in between two $\mathrm{PR}$ tests. The PR sessions lasted for $6 \mathrm{~h}$ during which the number of active lever responses required for each subsequent infusion increased during the session as follows: $1,2,4,6,9,12,15,20$, etc, following the exponential equation:

$$
\mathrm{NP}(\mathrm{n})=\left[5 . \mathrm{e}^{0.2-\mathrm{n}}\right]-5,
$$

with $n$ representing the injection rank (Richardson and Roberts, 1996). After the first FR1 was achieved, the breaking point (BP) was defined as the largest ratio completed before a period lasting $60 \mathrm{~min}$ or more during which no infusions were obtained.

An additional group of rats $(n=8)$ was trained to lever press for chocolate-flavored pellets on a FR1 schedule in daily 60-min sessions. Food PR tests were introduced once the training criterion was met (reinforcers earned $\geqslant 20$ for 3 consecutive days). In the PR test, RO5203648 (0, 3, $10 \mathrm{mg} / \mathrm{kg}$, i.p.) was administered $15 \mathrm{~min}$ before the start of the session. The PR session lasted for $6 \mathrm{~h}$ and had the same response requirement as the cocaine $\mathrm{PR}$ test. Each rat received three tests on different days separated by a drugfree food intake session.

\section{Food S-A}

Rats previously trained on cocaine S-A were left undisturbed for 2 weeks and were later trained to lever press for chocolate-flavored pellets. Food deprivation was not introduced. Once rats meet a criterion for lever presses (20 food pellets obtained in a 45 -min session on 3 consecutive sessions), we evaluated the effects of RO5203648 (0, 3, $10 \mathrm{mg} / \mathrm{kg}$ i.p.) and $\mathrm{RO} 5256390$ (0, 3, $10 \mathrm{mg} / \mathrm{kg}$ i.p.) administered as pretreatment $15 \mathrm{~min}$ before the intake tests. Each rat underwent three different tests lasting $45 \mathrm{~min}$ (ie, the same duration as the context-relapse tests), receiving $0,3,10 \mathrm{mg} / \mathrm{kg}$ i.p. of either compound in counterbalanced order.

\section{Fast Scan Cyclic Voltammetry (FSCV)}

Rats were anesthetized with halothane and decapitated. The brain was sectioned in cold carboxygenated artificial cerebrospinal fluid (aCSF) $(126 \mathrm{mM} \mathrm{NaCl}, 2.5 \mathrm{mM} \mathrm{KCl}$, $1.2 \mathrm{mM} \mathrm{NaH}_{2} \mathrm{PO}_{4}, 25 \mathrm{mM} \mathrm{NaHCO}, 2.4 \mathrm{mM} \mathrm{CaCl}, 11 \mathrm{mM}$ D-glucose, $1.2 \mathrm{mM} \mathrm{MgCl}_{2}$ ) on a VT1000S vibrating microtome (Leica Microsystems, Nussloch, Germany) at a thickness of $300 \mu \mathrm{m}$. Coronal slices containing the nucleus accumbens were allowed to recover for at least $1 \mathrm{~h}$ at room temperature in carboxygenated aCSF. For recordings, slices were superfused with $32{ }^{\circ} \mathrm{C}$ carboxygenated aCSF at a flow rate of $1 \mathrm{ml} / \mathrm{min}$. Experimental recordings started $20 \mathrm{~min}$ after transfer to the slice chamber. Carbon fiber electrodes (7 $\mu \mathrm{m}$, Goodfellow, Huntingdon, England) were made as previously described (Kawagoe et al, 1993; Kuhr and Wightman, 1986). They were trimmed to obtain a basal current between 140 and $180 \mathrm{nA}$. The electrodes were inserted $\sim 100 \mu \mathrm{M}$ into the nucleus accumbens slice. The potential of the working electrode was held at $-0.4 \mathrm{~V} v \mathrm{~s} \mathrm{Ag} /$ $\mathrm{AgCl}$ between scan and was ramped to $+1.3 \mathrm{~V}$ at $300 \mathrm{~V} / \mathrm{s}$ and back at $-0.4 \mathrm{~V}$ every $100 \mathrm{~ms}$ via an EVA8 amplifier (HEKA Elektronik, Germany). Axonal DA release in the nucleus accumbens was evoked using a twisted bipolar stimulating electrode (Plastics One, Roanoke, VA). Stimulations were delivered every $2 \mathrm{~min}$ by a single electrical pulse ( $1 \mathrm{~ms}$, single stimuli) and the pulse amplitude was $400 \mu \mathrm{A}$ The stimulus was delivered via a stimulus isolator (AMsystem, Carlsborg, WA). Background-subtracted cyclic voltammograms were obtained by subtracting the current obtained before the stimulation from all recordings. The peak oxidation current for DA in each voltammogram was converted into a measure of the DA concentration by postcalibration of the electrode using $1 \mu \mathrm{M}$ DA (Sigma-Aldrich, St Louis, MO). The TAAR1 partial agonist RO5203648 was superfused into slices for $10 \mathrm{~min}(0.1 \mu \mathrm{M})$ and washing period was $20 \mathrm{~min}$ followed by co-application of cocaine ( $3 \mu \mathrm{M}$, Sigma-Aldrich, Milan, Italy). Data were normalized to the average value of five recordings $(10 \mathrm{~min})$ of their respective control periods. TarHeel CV (ESA Biosciences, Chelmsford) was used for DA outflow analysis; Demon voltammetry and analysis software (Yorgason et al, 2011) was used for kinetic analysis of DA release and uptake (tau parameter).

\section{Statistical Analysis}

Behavioral data were analyzed by analysis of variance (ANOVA) with repeated measures when a within-subjects design was in use, followed by post hoc comparisons with the method of Newman-Keuls ( $\mathrm{N}-\mathrm{K})$ using the sampling error from the overall ANOVA as denominator. FSCV data were analyzed by one-way ANOVA followed by post hoc Bonferroni's multiple comparisons test. Simple two group comparisons were performed using Student's $t$-test where appropriate. Statistical significance was set at $\alpha=0.05$ for all experiments. All statistical analyses were performed using StatView 5.0 (SAS Institute, NC).

\section{RESULTS}

The Partial TAAR1 Agonist, R05203648, Blocks ContextInduced Relapse to Cocaine Seeking

We first tested the ability of RO5203648 to attenuate cocaine seeking after a 2 -week period of abstinence from 
cocaine S-A. Rats trained to self-administer cocaine $(n=7$; $0.5 \mathrm{mg} / \mathrm{kg} /$ infusion) on a FR3 schedule of reinforcement produced a significantly higher number of active lever presses $\left(p<0.01, \mathrm{~N}-\mathrm{K}\right.$ test; ANOVA $\mathrm{F}_{1,13}=116.98$, $p<0.001)$ and obtained more cocaine infusions $(p<0.01$, $\mathrm{N}-\mathrm{K}$ test; ANOVA $\left.\mathrm{F}_{1,13}=207.95, p<0.001\right)$ than rats responding for saline ( $n=8$; Figure $1 \mathrm{a}$ and inset).

After 2 weeks of abstinence, experimental and control rats were placed in the S-A chambers, levers were exposed but cocaine was not available. Rats showed robust relapse to drug-seeking upon re-exposure to the S-A chambers. ANOVA revealed significant main effects of drug (cocaine vs saline, $\mathrm{F}_{1,13}=44.78, p<0.001$ ), lever (active $v s$ inactive, $\left.\mathrm{F}_{1,13}=25.86, \quad p<0.001\right)$, and dose of RO5203648 $\left(\mathrm{F}_{2,26}=57.33, p<0.001\right)$, as well as a significant interaction between these factors $\left(\mathrm{F}_{2,26}=7.77, p<0.002\right.$; Figure 1b). RO5203648 completely blocked context-induced cocaine seeking. Post hoc comparisons showed significant effects of both the low ( $p<0.01, \mathrm{~N}-\mathrm{K}$ test) and the high dose $(p<0.01$, $\mathrm{N}-\mathrm{K}$ test) of RO5203648 on active lever presses. There was a comparatively lower but significant increase in the number of inactive lever responses made by cocaine-trained rats during the relapse test. Such an increase was similarly prevented by RO5203648 at both low $(p<0.01$, N-K test) and high $(p<0.01, \mathrm{~N}-\mathrm{K}$ test $)$ doses.

To control for potential motoric and/or motivational confounds, we next investigated the effects of RO5203648 on responding for a natural reinforcer (chocolate-flavored pellets). To approximate the response rates obtained in the cocaine relapse test, operant sessions were limited to 40 reinforcements, with rats $(n=8)$ responding on a FR1 schedule. Overall responding was not affected by RO5203648 at any dose. ANOVA did not reveal any significant effects of RO5203648 on food-maintained responding $\left(\mathrm{F}_{2,14}=1.39, p=0.283\right.$; Figure $\left.1 \mathrm{c}\right)$. However, analysis of the time course revealed a significant interaction with time $\left(\mathrm{F}_{4,28}=6.860, p<0.001\right)$. Rats treated with the high dose of RO5203648 obtained a similar amount of food pellets in the 45-min session but were slower to initiate responding, earning significantly fewer reinforcers early in the session (first $15 \mathrm{~min}$ ) and more later in the session (at the 30 and 45-min intervals, although differences at these two time points did not reach statistical significance) $(p<0.01$ by $\mathrm{N}-\mathrm{K}$ test; Figure $1 \mathrm{~d})$.

\section{The Full TAAR1 Agonist, R05256390, Suppresses Context-Induced Relapse to Cocaine Seeking}

We tested RO5256390 (0, 3, $10 \mathrm{mg} / \mathrm{kg}$ i.p.) under identical conditions to determine whether or not the effects of full agonist activation of TAAR1 were similar to those of partial activation. Rats responding for cocaine $(n=8)$ or saline $(n=6)$ infusions were trained on a FR3 schedule of reinforcement until they attained consistent performance. ANOVA was significant for lever presses $\left(F_{1,12}=196.61\right.$, $p<0.001)$ and reinforcers earned $\left(F_{1,12}=136.00, p<0.001\right)$, and both parameters were significantly increased in rats receiving cocaine infusions ( $p<0.01, \mathrm{~N}-\mathrm{K}$ test; Figure $1 \mathrm{e})$.
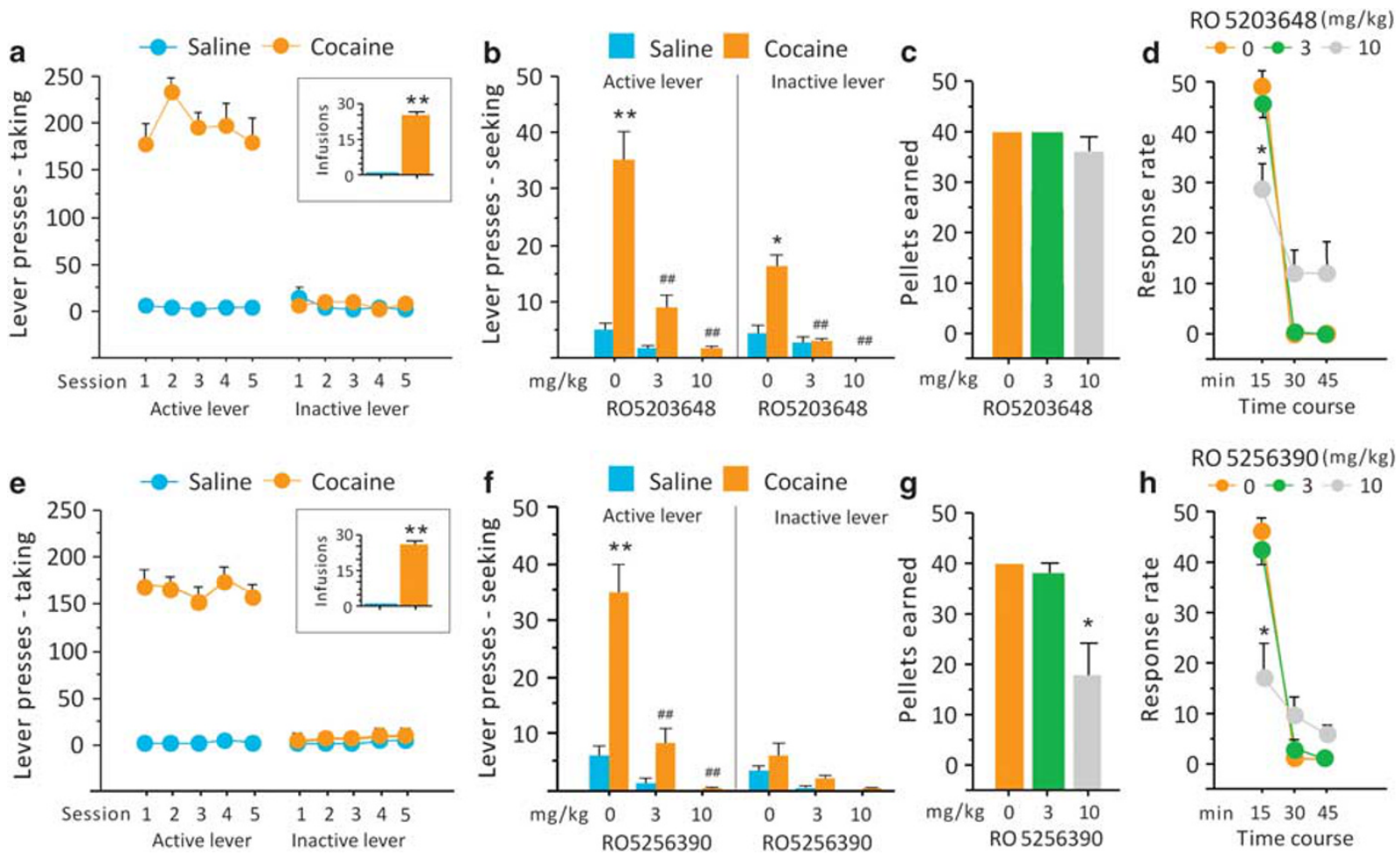

Figure I The partial TAARI agonist RO5203648 and the full agonist RO5256390 suppressed context-induced cocaine relapse at doses that spared foodmaintained responding. After consistent cocaine S-A performance $(\mathrm{a}, \mathrm{e})$ rats were pretreated with RO5203648 (0, $3,10 \mathrm{mg} / \mathrm{kg}$ i.p.) or with RO5256390 (0, 3, $10 \mathrm{mg} / \mathrm{kg}$ i.p.) on three different test sessions run in counterbalanced manner (b, f). Food responding was not affected by RO5203648 pretreatment (c) but the high dose slightly delayed responding (d). RO5256390 reduced overall food intake (g, h), but only at the high dose. *p <0.0 I, significantly different from control

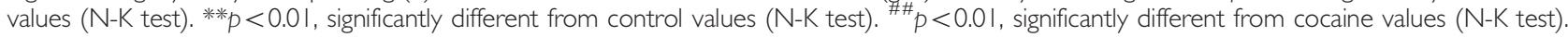


In the tests of relapse, analysis of active and inactive lever presses indicated significant main effects of drug (cocaine $v s$ saline, $\mathrm{F}_{1,12}=20.15, p<0.001$ ), lever (active $v s$ inactive, $F_{1,12}=32.73, p<0.001$ ), and dose of R05256390 $\left(\mathrm{F}_{2,24}=33.73, p<0.001\right)$, as well as a significant interaction between these factors $\left(F_{2,24}=13.83, P<0.001\right.$; Figure $\left.1 f\right)$. RO5256390 dose-dependently blocked cocaine seeking in the presence of cocaine-associated cues.

RO5256390 produced nonspecific effects at the high, but not low, dose. The high dose of RO5256390 reduced the overall number of food reinforcers earned $\left(\mathrm{F}_{2,14}=5.02\right.$, $p=0.023$; Figure 1g). Response rate was also delayed across time, but only by the high dose, with reduced number of reinforcers obtained in the initial $15 \mathrm{~min}$ of the session $\left(p<0.01, \quad \mathrm{~N}-\mathrm{K}\right.$ test; ANOVA $\mathrm{F}_{4,28}=15.07, \quad p<0.001$; Figure 1h).

\section{R05203648 Prevents Cocaine-Primed Reinstatement of Cocaine Seeking}

We next tested the ability of $\operatorname{RO} 5203648$ (0, 3, $10 \mathrm{mg} / \mathrm{kg}$ i.p.) to attenuate cocaine-primed reinstatement of drug seeking. Three experimental groups were trained to self-administer cocaine ( $n=7-8 ; 0.5 \mathrm{mg} / \mathrm{kg} /$ infusion) on a FR3 schedule of reinforcement. These three groups responded similarly and obtained a similar number of infusions in the last 5 days of cocaine S-A before extinction was introduced. Rats responding for saline $(n=5)$ showed very low rates of responding. ANOVA for lever presses during the last five cocaine S-A sessions revealed a significant effect of drug (cocaine vs saline, $\mathrm{F}_{3,23}=34.56, p<0.001$ ), a significant effect of lever (active $v s$ inactive, $\mathrm{F}_{1,23}=390.06, p<0.001$ ), as well as a significant interaction between these factors $\left(\mathrm{F}_{3,23}=35.83, p<0.001\right.$; Figure $\left.2 \mathrm{a}\right)$. Mean comparisons showed a significant difference between the control group and each of the three experimental groups in the number of active lever presses $(p<0.01, \mathrm{~N}-\mathrm{K}$ tests $)$, but not in the number of inactive lever presses. ANOVA for the average number of infusions over the 5 days showed a significant effect of group $\left(F_{3,23}=39.32, p<0.001\right)$, which was due to the higher number of infusions obtained by the three cocaine groups compared with the control group $(p<0.01$, by $\mathrm{N}-\mathrm{K}$ tests; Figure $2 \mathrm{a}$ inset).

During extinction, all but seven rats in the experimental groups gradually decreased responding on the active lever and reached the extinction criteria within 21 days. These seven rats were excluded from further analysis. Responding on the inactive lever was low throughout and did not differ between groups. A three-way ANOVA for lever presses during the last three extinction sessions showed a significant effect of group $\left(\mathrm{F}_{3,23}=4.74, p<0.01\right)$, a significant effect of lever $\left(\mathrm{F}_{1,23}=40.74, p<0.001\right)$, and a significant interaction between these factors $\left(\mathrm{F}_{3,23}=5.34\right.$, $p<0.01)$. Post hoc comparisons revealed no significant differences between the three groups previously trained in cocaine S-A (Figure 2b). After extinction, rats received RO5203648 (0, 3, or $10 \mathrm{mg} / \mathrm{kg}$, i.p.) followed $15 \mathrm{~min}$ after by cocaine $(10 \mathrm{mg} / \mathrm{kg}$, i.p.) or saline injection and were introduced in the S-A chambers with the levers exposed. Lever presses were recorded but had no consequences. The ANOVA calculated for the total number of lever presses in the reinstatement test showed a significant interaction between the factors drug (saline versus cocaine, $F_{1,23}=$ 18.81, $p<0.001$ ), lever (active $v s$ inactive, $F_{1,23}=47.69$, $p<0.001)$, and dose of R05203648 $\left(\mathrm{F}_{3,23}=7.62, p<0.001\right)$, as well as a significant interaction between these three factors $\left(\mathrm{F}_{3,23}=4.69, p<0.01\right.$; Figure $\left.2 \mathrm{c}\right)$. Post hoc comparisons showed that cocaine priming induced significantly higher response rates on the active lever, but not on the inactive lever, compared with saline treatment $(p<0.01$, by $\mathrm{N}-\mathrm{K}$ tests). Reinstatement was dose-dependently attenuated by RO5203648 at both the low $(p<0.01)$ and the high dose ( $p<0.01$, by N-K tests). RO5203648 did not in its own right (ie, when given before saline) produce renewed drug seeking at any dose.

For a closer examination of the effects of RO5203648 on cocaine-induced drug seeking, responses in the reinstatement test were analyzed in 20-min bins (Figure 2d). ANOVA revealed a significant effect of dose of RO5203648 $\left(\mathrm{F}_{2,12}=6.33, p<0.05\right)$, a significant effect of cocaine priming $\left(\mathrm{F}_{1,12}=9.28, p<0.05\right)$, and a significant effect of time $\left(\mathrm{F}_{8,96}=8.04, p<0.001\right)$, as well as a significant threeway interaction between these factors $\left(\mathrm{F}_{16,96}=5.98\right.$, $p<0.001)$. N-K tests showed that cocaine produced significantly higher number of active lever presses in the first $(p<0.01)$ and the second $(p<0.01) 20$-min bins, and that this effect was significantly attenuated by RO5203648 at both the low $(p<0.01)$ and the high $(p<0.01)$ doses.

\section{R05203648 Differentially Alters the Reinforcing Efficacy} of Cocaine and Food in a PR Schedule of Reinforcement

A group of rats $(n=9)$ underwent training on cocaine S-A under a FR3 schedule until they showed consistent responding. Rats received RO5203648 (0, 3, or $10 \mathrm{mg} / \mathrm{kg}$, i.p.) $15 \mathrm{~min}$ before the PR test. Overall, RO5203648 had no significant effect on the number of active lever presses made during the test $\left(\mathrm{F}_{2,16}=1.16, p=0.338\right)$ or on the number of infusions obtained $\left(\mathrm{F}_{2,16}=0.59, p=0.564\right)$.

However, the temporal parameters of responding for cocaine under the PR schedule were markedly altered by RO5203648 treatment. Active lever presses, cumulative number of cocaine infusions, and time to reach BP were analyzed. RO5203648 dose-dependently reduced active lever pressing in the early phases of the PR session, lengthened the accumulation of cocaine infusions, and delayed the time to reach BP. A two-way ANOVA for active lever presses showed a significant effect of time $\left(\mathrm{F}_{5,40}=13.37, p<0.001\right)$, and a significant interaction between treatment and time $\left(\mathrm{F}_{10,80}=11.08, p<0.001\right)$. Both doses of R05203648 produced a temporal shift to the right in the number of active lever presses made during the session (Figure 2e).

RO5203648 dose-dependently delayed the time point at which rats reached each successive cocaine infusion. ANOVA was calculated for the cumulative number of infusions obtained by the end of each 1-h bin, revealing a significant effect of dose of RO5203648 $\left(\mathrm{F}_{2,16}=6.74\right.$, $p<0.01)$, and a significant interaction with the factor, time (with six levels corresponding to each time bin) $\left(\mathrm{F}_{10,80}=18.72, p<0.001\right.$; Figure $\left.2 \mathrm{f}\right)$. Rats receiving vehicle injections rapidly obtained the first 10 infusions $(F R=40)$ by the end of the first hour bin and achieved BP by the second hour bin on average. Time to reach $\mathrm{BP}$ was significantly delayed by $\mathrm{RO5203648}\left(\mathrm{F}_{8,16}=20.31, p<0.001\right)$. 


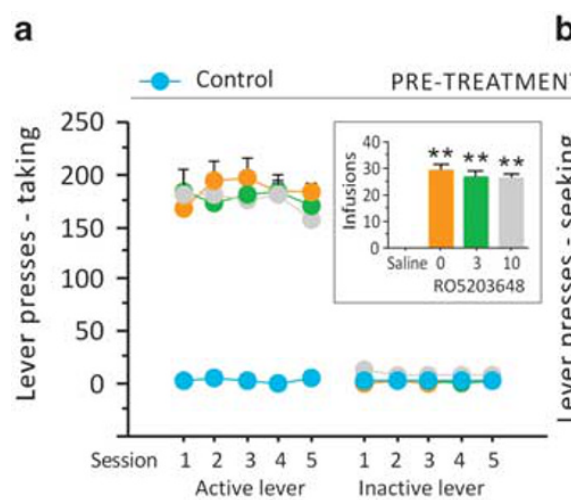

\section{b}

C
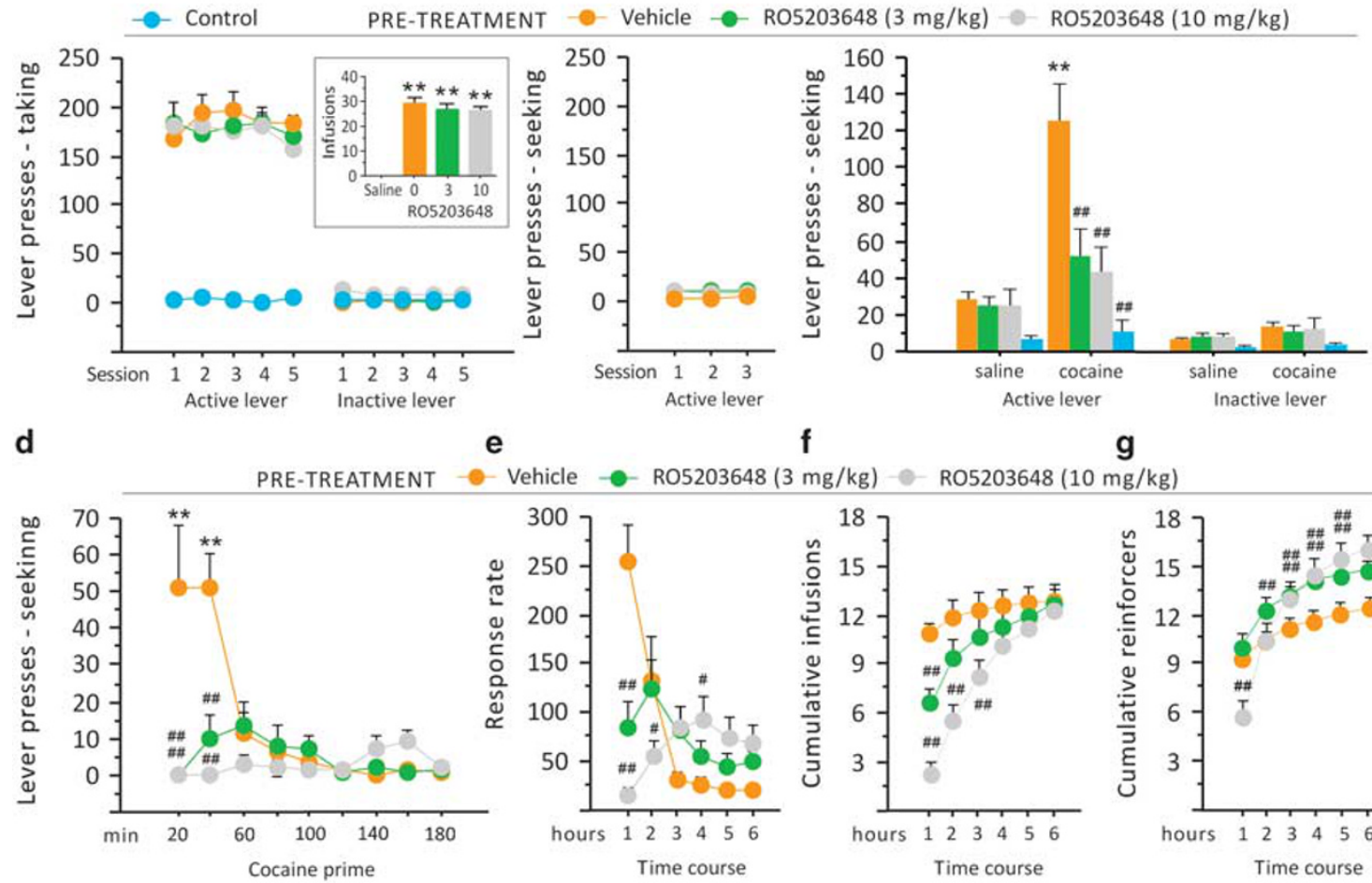

e Vehicle

f

g
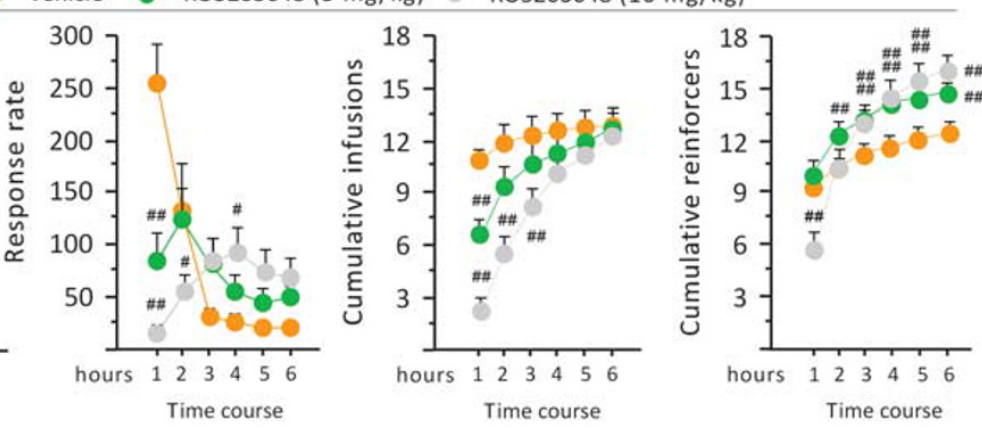

Figure 2 The partial TAARI agonist RO5203648 prevents cocaine-primed reinstatement of cocaine seeking and reduces cocaine, but not food, reinforcing efficacy. Several groups of rats were trained on cocaine S-A (a). This phase was followed by extinction training, which rats completed within 21 sessions (the last three sessions are shown in b). Cocaine treatment ( $10 \mathrm{mg} / \mathrm{kg}$ i.p.) produced strong reinstatement of cocaine seeking (c), which was dosedependently attenuated by RO5203648. In a PR schedule of reinforcement, RO5203648 dose-dependently shifted the cocaine response rate curve rightward (e) and delayed the time to reach BP ( $\mathrm{f}$ ). However, RO5203648 enhanced the reinforcing efficacy of food in the same paradigm (g) * $p<0.05$, significantly different from control values ( $N-K$ test). $* * *<0.01$, significantly different from control values ( $N-K$ test). ${ }^{\#} p<0.05$, significantly different from cocaine values (N-K test). ${ }^{\# \#} p<0.01$, significantly different from cocaine values ( $N-K$ test).

Means \pm SEM were $1.67 \pm 0.24 \mathrm{~h}, \quad 3.56 \pm 0.44 \mathrm{~h}, \quad$ and $4.56 \pm 0.34 \mathrm{~h}$ to reach BP for control, low and high doses of RO5203648, respectively, with both doses of the partial agonist being significantly different from control values $(p<0.01$ by N-K tests; Figure $2 \mathrm{f})$.

To compare the motivational effects of RO5203648 on cocaine and food reinforcement, another group of rats $(n=8)$ worked for food in the same PR procedure. RO5203648 significantly increased the number of active lever presses $\left(\mathrm{F}_{2,14}=15.06, p=0.0003\right)$ and the number of pellets obtained $\left(\mathrm{F}_{2,14}=19.23, p<0.0001\right)$ in the 6-h test. Post hoc comparisons showed that responses on the active lever were significantly increased by RO5203648 at both the low $(p<0.05$ by $\mathrm{N}-\mathrm{K}$ tests) and the high dose $(p<0.01$ by $\mathrm{N}-\mathrm{K}$ tests) and so was the number of pellets obtained $(p<0.01$ by N-K tests). Similarly, the BP achieved in the PR test was significantly increased by RO5203648 $\left(\mathrm{F}_{2,14}=16.89\right.$, $p=0.0002)$ in a dose-dependent manner.

A temporal breakdown of the 6-h test showed that RO5203648 changed the pattern of response for food. ANOVA revealed a significant effect of treatment $\left(\mathrm{F}_{2,14}=15.06\right.$, $p=0.0003)$ and time $\left(\mathrm{F}_{5,35}=12.54, p<0.0001\right)$, as well as a significant interaction between time and treatment $\left(\mathrm{F}_{10,70}=7.13, p<0.0001\right)$. At the low dose, RO5203648 significantly increased response rates at the second time point and subsequently. At the high dose, RO5203648 significantly reduced response rate during the first time bin
( $p<0.01$ by $\mathrm{N}-\mathrm{K}$ tests) but significantly increased it at the third time bin and at subsequent time points.

Correspondingly, the cumulative number of pellets obtained by the end of each time bin was also altered by RO5203648. ANOVA yielded a significant effect of treatment $\left(\mathrm{F}_{2,14}=4.85, p=0.025\right)$ and time $\left(\mathrm{F}_{5,35}=351.10\right.$, $p<0.0001)$, as well as a significant interaction between these factors $\left(F_{10,70}=21.23, p<0.0001\right)$. Both the low and the high dose of RO5203648 increased the number of pellets earned compared with the control condition. Means and SEM for the total number of pellets obtained at the end of the test were $12.50 \pm 0.50,14.88 \pm 0.40$, and $16.13 \pm 0.83$ for control, low, and high doses of RO5203648, respectively.

\section{R05203648 Prevents Cocaine-Stimulated DA Overflow in the Nucleus Accumbens}

To further elucidate the role of TAAR1 in regulating DA transmission and cocaine relapse, we evaluated the ability of a selective TAAR1 partial agonist RO5203648 to modulate electrically evoked DA overflow in the nucleus accumbens after cocaine exposure (Figure 3). Thus, we evaluated calibrated peak DA concentration for measuring DA release and DA uptake kinetics from an exponential fit curve using a least squares constrained exponential fit algorithm (National Instruments in Demon Voltammetry software, Wake Forest University Health Sciences, USA) by quantifying Tau 
a

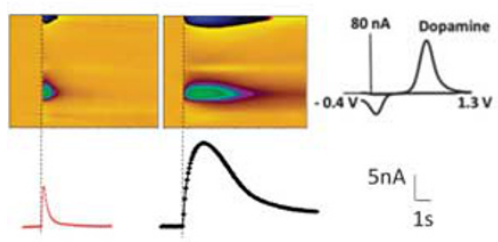

b

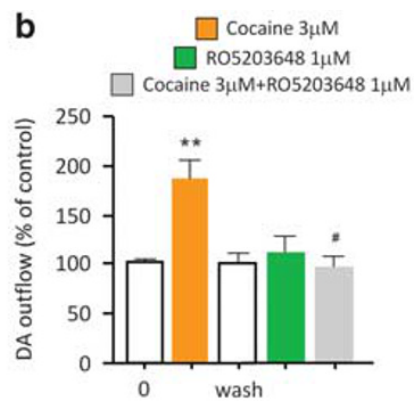

Figure 3 RO5203648 reduces cocaine-induced DA outflow from the rat nucleus accumbens slices. (a) DA outflow from rat brain slices monitored by FSCV in the rat nucleus accumbens slices. The background-subtracted cyclic voltammogram identifies the detected analyte as DA. The color plots represent the voltammetric currents (encoded in color in the $z$ axis) plotted against the applied potential $(y$ axis) and time ( $x$ axis). Representative traces at basal and cocaine conditions demonstrate the effect of cocaine $(3 \mu \mathrm{M})$ perfusion on DA outflow. Effects of cocaine and RO5203648 on evoked DA outflow (b) and DA uptake measure tau (c). Application of $3 \mu \mathrm{M}$ cocaine resulted in an expected significant increase in DA outflow and in the tau measure of DA uptake. After a washing period to restore basal DA levels, application of I $\mu$ M RO5203648 caused no significant effect on DA overflow or tau parameter. However, co-application of I $\mu \mathrm{M}$ RO5203648 reduced effect of cocaine $(3 \mu \mathrm{M})$ on DA outflow without causing significant alterations in effect of cocaine on tau ( ${ }^{*} p<0.05$, ${ }^{*} * 0.0$ I vs predrug levels; ${ }^{*} p<0.05$ vs cocaine-induced values; $n=5$ ).

parameter for DA uptake rates. Cocaine $(3 \mu \mathrm{M})$ induced an expected augmentation in evoked DA outflow, with the amplitude of the stimulated DA response rising to $183 \pm 25 \%$ of predrug values (Figures $3 \mathrm{a}$ and $\mathrm{b}, p<0.01$ vs predrug levels). Cocaine is a classical DA transporter inhibitor and produces predictable and well-defined alterations in DA uptake (John and Jones, 2007). These changes in uptake resulted in a protracted time course for DA levels to return to baseline, which became apparent in the current experiments as an increase in DA half-life values (Figures $3 \mathrm{~b}$ and c; $186 \pm 27 \% v s$ predrug levels, $p<0.05$ ).

After a washing period to restore the basal DA levels, we then examined the effect of application of RO5203648 $(1 \mu \mathrm{M})$ on evoked DA outflow. Application of the TAAR1 partial agonist by itself did not affect significantly DA outflow $(107 \pm 21 \%, p>0.05$, vs predrug values) or tau measure (106 $\pm 14 \%$ vs predrug levels, $p>0.05)$, suggesting that DA release and uptake are not influenced by the TAAR1 partial agonist. However, co-application of RO5203648 with cocaine significantly reduced cocaineinduced DA efflux $(95 \pm 9 \%, p<0.05$ vs cocaine-induced levels), without altering the effects of cocaine on tau measure of DA uptake (Tau; $150 \pm 13 \%, p<0.05$ vs predrug levels, $p<0.05 v s$ cocaine-induced levels) (Figures $3 \mathrm{~b}$ and $\mathrm{c})$.

\section{DISCUSSION}

The present data provide preclinical evidence supporting the development of TAAR1 agonists as therapeutic agents for the treatment of cocaine addiction. We determined that after protracted withdrawal from chronic cocaine S-A, treatment with either RO5203648 or RO5256390, partial and full TAAR1 agonists, respectively, completely prevented cocaine seeking in the context previously associated with cocaine taking. Both agonists were highly effective at doses that did not impair food-maintained responding. Moreover, after extinction of cocaine S-A, reinstatement of cocaine seeking by cocaine priming was dose-dependently decreased by the TAAR1 partial agonist, RO5203648. In a PR schedule of reinforcement, RO5203648 induced a dose- and time-dependent decrease in the ability of cocaine to sustain responding, markedly delaying the time to reach BP for cocaine S-A. In the same task, RO5203648 enhanced the reinforcing efficacy of food. Further, neurochemical measurements of DA overflow in the nucleus accumbens showed the ability of RO5203648 to reduce cocaine-induced DA accumulation without significantly altering DA uptake rates, suggesting that TAAR1 effectively regulates DA and cocaine's physiological effects.

Cocaine addiction is a common and costly health problem worldwide (Karila et al, 2012). Recurrent cycles of abuse, recovery, and relapse are defining features of cocaine addiction, thus developing medications that could aid in recovery and facilitate stable abstinence from cocaine would be highly beneficial from the medical standpoint. The recent discovery of a family of receptors sensitive to TAs (Bunzow et al, 2001; Borowsky et al, 2001) has generated a great deal of interest in the addiction field, but the clinical utility of these receptors as a target remains to be elucidated. Previous data showed that activation of TAAR1 strongly regulates DA transmission and reduces stimulant-induced behavioral effects. Evidence for the former came from genetic and electrophysiological studies. Taar1 knockout mice exhibited spontaneously elevated firing rate of DA neurons in the VTA (Lindemann et al, 2008) suggesting that TAAR1 is tonically active or constitutively activated to downregulate DA neuron firing frequency. Consistent with this notion, both the endogenous agonist p-tyramine and the selective TAAR1 agonists RO5166017 and RO5256390 inhibited the firing rate of midbrain DA neurons (Lindemann et al, 2008; Revel et al, 2011, 2013). By contrast, the selective antagonist EPPTB and the TAAR1 partial agonists RO5203648 and RO5263397 increased the basal spike frequency of DA neurons (Bradaia et al, 2009; Revel et al, 2012b, 2013). There is also strong evidence suggesting that TAAR1 activation can modulate the potentiation of DA transmission induced by psychomotor stimulants. Mice lacking taar1 displayed augmented amphetamine-stimulated striatal DA release and amphetamine-elicited locomotor activity (Lindemann et al, 2008), while transgenic mice overexpressing TAAR1 exhibited hyposensitivity to amphetamine, both neurochemically and behaviorally 
(Revel et al, 2012a). Further evidence of the inhibitory control of TAAR1 over DA transmission was afforded by the observation that the selective full and partial agonists, RO5166017, RO5203648, RO5256390, and RO5263397, reduced the locomotor- and stereotypy-stimulating effects of cocaine treatment (Revel et al, 2011, 2012b, 2013). Moreover, previous studies found that the TAAR1 partial agonist tested in this study, RO5203648, dose-dependently reduced cocaine $\mathrm{S}-\mathrm{A}$ (Revel et al, 2012b). Based on these findings, we used clinically relevant animal models to evaluate the ability of TAAR1 agonists to modulate behaviors associated with cocaine addiction symptomatology, specifically relapse, as one of the major obstacles addicts encounter on the path to recovery.

First, we used a model of context-induced renewal of drug seeking without prior extinction, which approximates 'real life' situations in which addicts re-experience contexts associated with past drug-taking behavior (Fuchs et al, 2006; Ferragud et al, 2009). After long-term abstinence, neither cocaine nor previously contingent cues (eg, the light paired with cocaine infusions during the S-A phase) were presented upon lever responding, thus allowing the dissociation of drug seeking from responding maintained by cocaine or by explicit conditioned reinforcers. It is known that exposure to drug-related stimuli induces elevations in mesolimbic DA transmission, measured with microdialysis (Fontana et al, 1993), and produces marked changes in gene expression in the medial prefrontal cortex, orbitofrontal cortex, dorsal striatum, and nucleus accumbens (Hearing et al, 2008a,b). In addition, fast cycling voltammetry technology revealed rapid surges in DA in the nucleus accumbens that coincided with the initiation of drug-seeking behaviors (Phillips et al, 2003). Based on the aforementioned evidence suggesting a dampening effect of TAAR1 activation on DA signaling, we predicted that activating TAAR1 in animals re-exposed to the context previously associated with cocaine would attenuate cocaine seeking by reducing contextual cue-elicited DA transmission. Our current results confirmed this prediction. Consistent with a decrease in otherwise augmented contextual cue-elicited DA signaling, the present results showed that both RO5203648 and RO5256390 significantly reduced cocaine seeking. Importantly, both compounds were highly effective at doses that had no significant influence on a similar lever pressing task maintained by food, suggesting that the agonists can act within a wide therapeutic window.

After extinction of cocaine S-A, cocaine seeking can be precipitated by several stimuli, including re-exposure to cocaine itself. Strong elevations in DA signaling are expected to mediate cocaine seeking after cocaine priming in an extinction-reinstatement model of relapse. There is agreement that projections from the VTA to the medial prefrontal cortex may critically mediate cocaine-induced reinstatement through stimulation of glutamate afferents to the nucleus accumbens (McFarland et al, 2003; Kalivas and McFarland, 2003). In addition, DA projections to the nucleus accumbens itself may have an important role to play. Infusions of cocaine (Park et al, 2002) or DA (Cornish and Kalivas, 2000) into the nucleus accumbens reinstated extinguished cocaine seeking. We directly tested the hypothesis that TAAR1 activation would prevent cocaine- primed reinstatement. Following consistent cocaine S-A and extinction, cocaine-priming produced robust reinstatement of cocaine seeking, and this effect was dose-dependently attenuated by RO5203648. Importantly, RO5203648 failed to reinstate cocaine seeking when administered alone (ie, followed by vehicle injection instead of cocaine), displaying therefore a psychopharmacological profile that is unlike some the psychomotor stimulants and hallucinogenic drugs that bind nonselectively to TAAR1, including amphetamine and 3,4-methylenedioxymethamphetamine, which do produce cross-reinstatement of extinguished cocaine seeking (de and Stewart, 1981; Schenk et al, 2008). The finding that TAAR1 agonist treatment reduced both contextual renewal of drug seeking and cocaine-primed reinstatement is important because the neural substrates mediating such behaviors overlap only partially (Fuchs et al, 2006; Kalivas, 2008).

Furthermore, the current results using a PR schedule of reinforcement are consistent with previous data indicating that partial TAAR1 activation blocks cocaine S-A (Revel et $a l, 2012 b)$. The present data additionally suggest that the partial agonist is likely to make cocaine less reinforcing, which is yet another desirable feature for a pharmacological agent to have if it is designed as a therapeutic approach for cocaine addiction. In addition, in the same PR paradigm, RO5203648 increased response rates and elevated the BP for food pellets, suggesting that cocaine taking and food reinforcement are mediated by different mechanisms in the brain and that TAAR1 treatment targets cocaine-related behaviors specifically.

Cocaine is known to increase extracellular concentration of DA in the nucleus accumbens primarily by blocking reuptake of physiologically released DA (Greco and Garris, 2003). We used fast cycling voltammetry in slices through the nucleus accumbens to assess the ability of RO5203648 to modulate cocaine-stimulated DA transmission. As predicted, RO5203648 diminished cocaine-induced DA overflow in the nucleus accumbens. However, RO5203648 did not significantly affect the tau measure of DA uptake in the presence of cocaine, thus suggesting that TAAR 1 regulation of cocaine's effects on DA levels is likely to be independent of direct actions on the DAT. Among possible mechanisms for such modulation, known interactions with DA autoreceptors, which may be regulated by TAAR1 in opposing manner (Espinoza et al, 2011; Ledonne et al, 2010), or indirect actions of TAAR1 at the DAT (Xie et al, 2007; Xie and Miller, 2007), may be primarily considered. As the DA uptake blocking activity of cocaine seems not to be affected by RO5203648 pretreatment, it is likely that TAAR1 activation causes a decrease in DA release kinetics resulting in less accumulation of extracellular DA resulting from blockade of the DAT by cocaine. It is noteworthy that while in the present experiments RO5203648 did not stimulate DA overflow in the nucleus accumbens when administered alone, previous evidence indicated that RO5203648 is able to enhance the firing rate of midbrain DA neurons under specific conditions (Revel et al, 2012b). These effects highlight the remarkable neuromodulatory properties of TAAR1 and suggest that its actions may be beneficial during critical phases of the addiction cycle, including not only when DA levels increase during intoxication but also when abstinence and altered DA function may drive anhedonia and craving (Koob and Le, 2001; Melis et al, 2005). 
In summary, the present data demonstrate a strong ability of TAAR1 agonists to prevent cocaine-related behaviors of evident clinical relevance, including cocaine seeking after abstinence in the presence of cocaine-associated cues and cocaine-primed reinstatement of cocaine seeking following extinction of cocaine S-A. These finding strongly support the development of TAAR1 agonists as candidate medications for cocaine addiction.

\section{FUNDING AND DISCLOSURE}

$\mathrm{MCH}$ is an employee of F Hoffmann-La Roche. The remaining authors declare no conflict of interest.

\section{ACKNOWLEDGEMENTS}

This work was supported by grants to JJC from the Spanish Ministry of Health (ISCIII, grant PI10/00297), the Lottery Health Board of New Zealand (Ministry of Internal Affairs), and the Department of Psychology, University of Canterbury, New Zealand, and grants to RRG from the Fondazione Compagnia di San Paolo (Torino, Italy) and F Hoffman-La Roche.

\section{REFERENCES}

Berry MD (2004). Mammalian central nervous system trace amines. Pharmacologic amphetamines, physiologic neuromodulators. J Neurochem 90: 257-271.

Berry MD (2007). The potential of trace amines and their receptors for treating neurological and psychiatric diseases. Rev Recent Clin Trials 2: 3-19.

Borowsky B, Adham N, Jones KA, Raddatz R, Artymyshyn R, Ogozalek KL et al (2001). Trace amines: identification of a family of mammalian G protein-coupled receptors. Proc Natl Acad Sci USA 98: 8966-8971.

Bradaia A, Trube G, Stalder H, Norcross RD, Ozmen L, Wettstein JG et al (2009). The selective antagonist EPPTB reveals TAAR1-mediated regulatory mechanisms in dopaminergic neurons of the mesolimbic system. Proc Natl Acad Sci USA 106: 20081-20086.

Bunzow JR, Sonders MS, Arttamangkul S, Harrison LM, Zhang G, Quigley DI et al (2001). Amphetamine, 3,4-methylenedioxymethamphetamine, lysergic acid diethylamide, and metabolites of the catecholamine neurotransmitters are agonists of a rat trace amine receptor. Mol Pharmacol 60: 1181-1188.

Cornish JL, Kalivas PW (2000). Glutamate transmission in the nucleus accumbens mediates relapse in cocaine addiction. J Neurosci 20: RC89.

de WH, Stewart J (1981). Reinstatement of cocaine-reinforced responding in the rat. Psychopharmacology (Berl) 75: 134-143.

Espinoza S, Salahpour A, Masri B, Sotnikova TD, Messa M, Barak LS et al (2011). Functional interaction between trace amineassociated receptor 1 and dopamine D2 receptor. Mol Pharmacol 80: $416-425$.

Ferragud A, Velazquez-Sanchez C, Hernandez-Rabaza V, Nacher A, Merino V, Carda M et al (2009). A dopamine transport inhibitor with markedly low abuse liability suppresses cocaine self-administration in the rat. Psychopharmacology (Berl) 207: 281-289.

Fontana DJ, Post RM, Pert A (1993). Conditioned increases in mesolimbic dopamine overflow by stimuli associated with cocaine. Brain Res 629: 31-39.
Fuchs RA, Branham RK, See RE (2006). Different neural substrates mediate cocaine seeking after abstinence versus extinction training: a critical role for the dorsolateral caudate-putamen. J Neurosci 26: 3584-3588.

Grandy DK (2007). Trace amine-associated receptor 1-family archetype or iconoclast? Pharmacol Ther 116: 355-390.

Greco PG, Garris PA (2003). In vivo interaction of cocaine with the dopamine transporter as measured by voltammetry. Eur $J$ Pharmacol 479: 117-125.

Hearing MC, Miller SW, See RE, McGinty JF (2008a). Relapse to cocaine seeking increases activity-regulated gene expression differentially in the prefrontal cortex of abstinent rats. Psychopharmacology (Berl) 198: 77-91.

Hearing MC, See RE, McGinty JF (2008b). Relapse to cocaineseeking increases activity-regulated gene expression differentially in the striatum and cerebral cortex of rats following short or long periods of abstinence. Brain Struct Funct 213: 215-227.

John CE, Jones SR (2007). Voltammetric characterization of the effect of monoamine uptake inhibitors and releasers on dopamine and serotonin uptake in mouse caudate-putamen and substantia nigra slices. Neuropharmacology 52: 1596-1605.

Kalivas PW (2008). Addiction as a pathology in prefrontal cortical regulation of corticostriatal habit circuitry. Neurotox Res 14: 185-189.

Kalivas PW, McFarland K (2003). Brain circuitry and the reinstatement of cocaine-seeking behavior. Psychopharmacology (Berl) 168: 44-56.

Karila L, Petit A, Lowenstein W, Reynaud M (2012). Diagnosis and consequences of cocaine addiction. Curr Med Chem 19: $5612-5618$

Kawagoe KT, Zimmerman JB, Wightman RM (1993). Principles of voltammetry and microelectrode surface states. J Neurosci Methods 48: 225-240.

Koob GF, Le MM (2001). Drug addiction, dysregulation of reward, and allostasis. Neuropsychopharmacology 24: 97-129.

Kuhr WG, Wightman RM (1986). Real-time measurement of dopamine release in rat brain. Brain Res 381: 168-171.

Ledonne A, Federici M, Giustizieri M, Pessia M, Imbrici P, Millan $\mathrm{MJ}$ et al (2010). Trace amines depress $\mathrm{D}(2)$-autoreceptormediated responses on midbrain dopaminergic cells. $\mathrm{Br} J$ Pharmacol 160: 1509-1520.

Lewin AH, Miller GM, Gilmour B (2011). Trace amine-associated receptor 1 is a stereoselective binding site for compounds in the amphetamine class. Bioorg Med Chem 19: 7044-7048.

Lindemann L, Ebeling M, Kratochwil NA, Bunzow JR, Grandy DK, Hoener MC (2005). Trace amine-associated receptors form structurally and functionally distinct subfamilies of novel G protein-coupled receptors. Genomics 85: 372-385.

Lindemann L, Hoener MC (2005). A renaissance in trace amines inspired by a novel GPCR family. Trends Pharmacol Sci 26: 274-281.

Lindemann L, Meyer CA, Jeanneau K, Bradaia A, Ozmen L, Bluethmann $\mathrm{H}$ et al (2008). Trace amine-associated receptor 1 modulates dopaminergic activity. J Pharmacol Exp Ther 324: 948-956.

McFarland K, Lapish CC, Kalivas PW (2003). Prefrontal glutamate release into the core of the nucleus accumbens mediates cocaineinduced reinstatement of drug-seeking behavior. J Neurosci 23: 3531-3537.

Melis M, Spiga S, Diana M (2005). The dopamine hypothesis of drug addiction: hypodopaminergic state. Int Rev Neurobiol 63: 101-154.

Miller GM, Verrico CD, Jassen A, Konar M, Yang H, Panas $\mathrm{H}$ et al (2005). Primate trace amine receptor 1 modulation by the dopamine transporter. J Pharmacol Exp Ther 313: 983-994.

Park WK, Bari AA, Jey AR, Anderson SM, Spealman RD, Rowlett JK et al (2002). Cocaine administered into the medial prefrontal 
cortex reinstates cocaine-seeking behavior by increasing AMPA receptor-mediated glutamate transmission in the nucleus accumbens. J Neurosci 22: 2916-2925.

Phillips PE, Stuber GD, Heien ML, Wightman RM, Carelli RM (2003). Subsecond dopamine release promotes cocaine seeking. Nature 422: 614-618.

Reese EA, Norimatsu Y, Grandy MS, Suchland KL, Bunzow JR, Grandy DK (2014). Exploring the determinants of trace amineassociated receptor 1's functional selectivity for the stereoisomers of amphetamine and methamphetamine. J Med Chem 57: $378-390$.

Revel FG, Meyer CA, Bradaia A, Jeanneau K, Calcagno E, Andre CB et al (2012a). Brain-specific overexpression of trace amineassociated receptor 1 alters monoaminergic neurotransmission and decreases sensitivity to amphetamine. Neuropsychopharmacology 37: 2580-2592.

Revel FG, Moreau JL, Gainetdinov RR, Bradaia A, Sotnikova TD, Mory $\mathrm{R}$ et al (2011). TAAR1 activation modulates monoaminergic neurotransmission, preventing hyperdopaminergic and hypoglutamatergic activity. Proc Natl Acad Sci USA 108: 8485-8490.

Revel FG, Moreau JL, Gainetdinov RR, Ferragud A, Velazquez-Sanchez C, Sotnikova TD et al (2012b). Trace amine-associated receptor 1 partial agonism reveals novel paradigm for neuropsychiatric therapeutics. Biol Psychiatry 72: 934-942.
Revel FG, Moreau JL, Pouzet B, Mory R, Bradaia A, Buchy D et al (2013). A new perspective for schizophrenia: TAAR1 agonists reveal antipsychotic- and antidepressant-like activity, improve cognition and control body weight. Mol Psychiatry 18: 543-556.

Richardson NR, Roberts DC (1996). Progressive ratio schedules in drug self-administration studies in rats: a method to evaluate reinforcing efficacy. J Neurosci Methods 66: 1-11.

Schenk S, Hely L, Gittings D, Lake B, Daniela E (2008). Effects of priming injections of MDMA and cocaine on reinstatement of. Drug Alcohol Depend 96: 249-255.

Velazquez-Sanchez C, Ferragud A, Ramos-Miguel A, Garcia-Sevilla JA, Canales JJ (2013). Substituting a long-acting dopamine uptake inhibitor for cocaine prevents relapse to cocaine seeking. Addict Biol 18: 633-643.

Xie Z, Miller GM (2007). Trace amine-associated receptor 1 is a modulator of the dopamine transporter. J Pharmacol Exp Ther 321: 128-136.

Xie Z, Westmoreland SV, Bahn ME, Chen GL, Yang H, Vallender EJ et al (2007). Rhesus monkey trace amine-associated receptor 1 signaling: enhancement by monoamine transporters and attenuation by the D2 autoreceptor in vitro. J Pharmacol Exp Ther 321: 116-127.

Yorgason JT, Espana RA, Jones SR (2011). Demon voltammetry and analysis software: analysis of cocaine-induced alterations in dopamine signaling using multiple kinetic measures. J Neurosci Methods 202: 158-164. 